\title{
EL DERECHO CONSTITUCIONAL ECONÓMICO EN EL PERÚ
}

\author{
Manuel Arnaldo Castillo Calle ${ }^{1}\left({ }^{*}\right)(* *)$ \\ Centro Latinoamericano de Derecho Constitucional \\ Universidad Inca Garcilaso de la Vega, Perú
}

http://dx.doi.org/10.5209/rev_NOMA.2013.42352

\begin{abstract}
Resumen.- El presente artículo tiene como finalidad brindar algunos alcances sobre cómo se encuentra regulado el Régimen Económico en nuestra Magna Lex, ya que como sabemos en nuestra historia constitucional la regulación de aspectos económicos en una constitución no ha sido una práctica que haya existido siempre, muy por el contrario, una parte económica se incluye en una constitución recién en el siglo XX, sumándose a aquellas dos partes tradicionales de componen la misma, que vienen a ser la parte dogmática referida a los derechos y deberes de la persona o del ciudadano, y, una parte orgánica, es decir, aquella dedicada a tratar lo relacionado a la organización del Estado y las diferentes funciones que cumplen todos y cada uno de sus organismos que lo componen.
\end{abstract}

Palabras clave.- régimen económico, parte dogmatica, parte orgánica, texto constitucional, neocapitalismo, socialismo democrático, preámbulo, economía social de mercado, derechos fundamentales, Estado

\begin{abstract}
This article is intended to provide some scope on how the Economic System is regulated in our Magna Lex, as we know in our constitutional history of economic regulation in a constitution is not a practice that has always existed, well Conversely, an economic part is included in a new constitution in the twentieth century, adding to those two traditional parties comprising the same, which come to be the dogmatic referred to the rights and duties of the person or citizen, and, an organic part, that is, one dedicated to addressing matters related to the state organization and the different functions performed by each and every one of its component agencies.
\end{abstract}

Keywords.- economic system, partly dogmatic, partly organic constitution, neo-capitalism, democratic socialism, preamble, social market economy, fundamental rights, the State

\footnotetext{
${ }^{1}$ Director Ejecutivo del Centro Latinoamericano de Derecho Constitucional, Egresado de la Facultad de Derecho y Ciencias Políticas de la Universidad Inca Garcilaso de la Vega, Miembro del Comité Consultivo de la Revista de Derecho Penal y Criminología de la Universidad Nacional de Córdoba (Argentina), Director del área de Derecho Constitucional del Centro de Investigaciones Philos luris (Perú), Articulista de la Revista de Facultad de Derecho de la Pontificia Universidad Católica de Chile, Actualmente viene desempeñándose como Docente de Derecho Constitucional y Procesal Constitucional, Estudios en Materia de Conciliación Extrajudicial y Conciliación Extrajudicial Especializada en Familia, Conferencista en temas de Derecho Constitucional a nivel nacional.
} 
A Néstor Pedro Sagüés, digno representante del Derecho Constitucional Argentino

\section{INTRODUCCIÓN}

Toda Constitución debe de contar con tres partes: preámbulo, parte dogmática y parte orgánica. El preámbulo suele tener un conjunto de enunciados solemnes de introducción que señalan quien hace la Constitución, cuáles son sus fines, cuál es la tendencia y el espíritu del texto constitucional; no tiene carácter normativo vinculante, pero tiene el carácter inspirador de una declaración de principios y valores que sirve de guía para la interpretación y la elaboración de normas. La parte dogmática contiene los derechos fundamentales de las personas y precede a la parte orgánica como mensaje de su supremacía sobre la sociedad y el Estado. La parte orgánica contiene las normas que determinan la forma de Estado y de gobierno, su organización, funciones, competencias, responsabilidades y demás aspectos. Esta división no es estricta, pues en la parte dogmática podemos encontrar algunos dispositivos de carácter orgánico y en el parte orgánica podemos encontrar algunas disposiciones de carácter dogmático.

Si nos enfocamos en la Parte Orgánica existen un conjunto de dispositivos que se distinguen de los demás por estar relacionados a la actividad económica del país. Así tenemos, aquellos que limitan la actividad económica del Estado; le imponen obligaciones y responsabilidades en materia económica; regulan su actividad recaudadora y distributiva de los recursos públicos; así como establecen derechos y libertades económicas en favor de los particulares. Este conjunto de dispositivos constitucionales han sido agrupados en lo que se denomina la "Constitución Económica"; no se trata de una Constitución distinta a la que conocemos, sino un aspecto de ella, que se diferencia por su especialidad, importancia y organicidad.

A decir de nuestro máximo intérprete de la Constitución, el mismo que viene a ser el Tribunal Constitucional del Perú ${ }^{2}$ también ha ensayado definiciones; por una lado dice que son "normas orientadas a establecer las pautas básicas sobre las que se fundan el régimen económico de una sociedad"; por otro lado, que son "disposiciones que suponen el establecimiento de un plexo normativo que tiene como finalidad configurar el ámbito jurídico en el cual se desarrollarán la actividad económica de nuestro país, y cuyo propósito es que la actuación del Estado y los ciudadanos sea coherente con la naturaleza y los fines del Estado social y democrático de Derecho". Nosotros proponemos que la Constitución Económica consiste en el conjunto de normas constitucionales que establecen el marco

\footnotetext{
${ }^{2}$ STC No 088-2003-Al/TC, www.tc.gob.pe.
} 
jurídico fundamental y orgánico, que regula la actividad económica de un país, tanto las relaciones económicas del Estado con los ciudadanos y entre éstos.

En la historia de las trece constituciones que ha tenido el Perú, ninguna hasta la Constitución de 1979 tuvo un capitulo especifico sobre el régimen económico. Como casi la totalidad de constituciones latinoamericanas contemporáneas, las normas en materia económica estuvieron reguladas en las secciones sobre derechos de las personas o de las garantías constitucionales.

La Constitución de 1979 por primera vez incluyo un capitulo especifico sobre el régimen económico, el mismo que se ha mantenido en la Magna Lex de 1993.

\section{ALCANCES SOBRE ¿QUÉ ES EL DERECHO CONSTITUCIONAL ECONOMICO?}

El derecho de la economía desde una perspectiva sustantiva, confluye las normas e instrumentos jurídicos a través de los cuales el Estado dirige la actividad económica, fundamentalmente la Constitución económica.

La Constitución entre otros posibles significados, es la norma suprema que, inspirada en valores superiores, determina la ordenación jurídica de la sociedad. Y dado el alcance y trascendencia que tiene la economía en la vida social, es fundamental que la Constitución recoja los principios jurídicos mas importantes a los que debe someterse la ordenación de esa realidad más aún, cuando, en momentos como los actuales, el Estado asume roles que tienen gran incidencia en su quehacer y configuración. En ese orden de ideas, compartimos el criterio de que la participación y las prerrogativas del Estado en la vida económica constituyen en nuestros días uno de los problemas centrales del constitucionalismo.

Creemos pertinente diferenciar con claridad la regulación del Derecho Publico de la Economía. El fin primordial de la regulación, de origen anglosajón, es el reforzamiento del mercado allí donde ha decaído su capacidad de proporcionar eficiencia en la asignación de los recursos. Su finalidad es fundamentalmente económica. Mientras que el derecho público de la economía, tal como se extiende en el contexto europeo continental, tiene un contenido más amplio de la regulación económica, pues abarca todas las posibles manifestaciones de la intervención del Estado, esto es, tanto aquellas que persiguen una finalidad como las que procuran otros fines y de modo marcado fines distributivos. En esta concepción, que es la que seguimos, el fundamento constitucional de la ordenación económica de los derechos constitucionales, como la libertad de la empresa, o los Principios Generales del Régimen Económico³.

\footnotetext{
3 Ibídem, pp. 242-243.
} 
En los tiempos presentes adquiere vigencia el pensamiento del economista GALBRAITH ${ }^{4}$, quien señalo cuatro factores que obligan a la intervención y regulación pública, las mismas que viene a ser:

- La protección del medio ambiente

- La protección de los más vulnerables de los empleados por al aparato productivo contra los efectos adversos de la maquina económica.

- La propensión de la economía a producir o vender bienes y servicios deficientes o materialmente perjudiciales.

- $\quad$ Las tendencias al interior del sistema económico que son autodestructivas para su eficaz funcionamiento.

Así, en el derecho administrativo económico hay una variedad muy diversa de formas de intervención del Estado en la economía: el orden publico económico es un titulo que legitima la intervención del Estado mediante autorizaciones, inspecciones, sanciones e intervenciones de empresas; la actividad administrativa de fomento del desarrollo económico mediante subvenciones y construcción de obras públicas; la actividad administrativa prestacional o de servicio público; y la intervención directa mediante empresas públicas.

En el derecho público comparado no es la regla que exista una sección de la constitución relativa a una materia, como el régimen económico, que corresponde más bien a las políticas de gobierno antes de que a la estructura del Estado. Regular el régimen económico de la sociedad y el gobierno debe ser, en principio, competencia solo legislativa; hacerlo a nivel constitucional puede reducir en extremo las opciones de política económica y las alternativas de desarrollo. En el caso de la actual constitución que limita la soberanía del Estado en asuntos tan importantes como la exploración y explotación de los recursos naturales o el tratamiento a la inversión nacional.

\section{EL REGIMEN ECONOMICO CONSTITUCIONAL EN EL PERÚ}

La regulación de aspectos económicos en una constitución no es una práctica que haya existido siempre en el Constitucionalismo. Así, una parte económica se incluye en una Constitución recién en el siglo XX, sumándose a aquellas dos partes tradicionales de la misma, como son una parte dogmatica referida a los derechos y deberes de la persona y, una parte orgánica, es decir aquella relacionada a tratar los diferentes poderes del Estado y sus correspondientes funciones.

Una de las partes más importantes de la Constitución Política del Perú es la destinada a establecer el régimen económico constitucional. Así, podemos describir que el artículo 58 de nuestra Carta Política señala que el Perú ostenta un régimen Constitucional Social de Mercado. Pero debemos tener muy en cuenta

${ }^{4}$ GALBRAITH 1997, p. 98. 
que no debemos de confundir la economía social de mercado con la Economía de mercado, pues si bien es cierto que ambas contienen elementos en común, también es cierto que ambas presentan diferencias sustanciales.

De acuerdo a nuestra Constitución Política del Perú, la Economía Social de Mercado, presenta las siguientes características:

a) Intervención subsidiaria del Estado en la Economía.- El Estado peruano puede intervenir subsidiariamente en el ámbito de la producción u distribución de bienes o en la prestación de los llamados servicios, solo cuando se encuentre fehacientemente acreditado que por la inacción de la iniciativa privada, dicha provisión no atiende las demandas de la población.

Debemos tener en cuenta que de acuerdo a lo antes señalado, no significa que el Estado quede excluido de desempeñar permanentemente su función de orientar el desarrollo sostenible del país, motivo por el cual nuestra carta magna le impone el deber de ocuparse principalmente en áreas de salud, educación, infraestructura, etc.

b) Libre mercado.- El mercado es el espacio donde confluyen ofertantes y demandantes para realizar el intercambio de bienes y servicios, en él se forman las condiciones de los contratos bajo las reglas económicas que rigen su funcionamiento. Pero el Estado tiene un deber fundamental en este tipo de actividades que es vigilar y facilitar la libre competencia, además de la protección de los consumidores que se constituyen como agentes económicos de importancia para el mercado.

c) Actuación solidaria del Estado.- La Economía Social de Mercado se enmarca en la concepción del Estado; que es caracterizado por nuestra Constitución como un Estado Social y Democrático de Derecho, En tal sentido, el régimen económico se encuentra guiado por valores democráticos, participativos y tienen como finalidad alcanzar el bienestar social compartido de la población.

d) Libertad para el ejercicio de la actividad económica.- La Constitución Política del Perú de 1993 establece que la iniciativa privada es libre, garantizando de esta manera la libertad de empresa, industria, comercio y la libertad de trabajo.

\section{LA DIFINICIÓN DE CONSTITUCIÓN ECONOMICA.}

Es recién en las primeras décadas del siglo $X X$ que se da inicio a una más amplia intervención económica del Estado. Sea en la determinación de de la condiciones de seguridad y de salud en los centros de trabajo, como dueño de empresas, en la protección del medio ambiente, el uso del suelo, etc. hasta llegar a la regulación 
administrativa de actividad cuya prestación es esencial para atender a las necesidades vitales de la comunidad mediante la concesión de servicios públicos. La teoría del servicio público es consolidada por la Escuela Francesa de Burdeos, hasta el extremo que un autor clásico como el Frances Duhuit sostenía que: "El Estado no es, como se ha pretendido hace, y como durante algún tiempo se ha creído que era un poder de mando, una soberanía, es una cooperación de servicios públicos organizados y controlados por los gobernantes.

En el siglo $X X$, con el proceso denominado del paso del Estado Liberal de Derecho al Estado Social de Derecho, que se inicia propiamente del Derecho Constitucional Económico. Cabe subrayar que, en este proceso histórico, el primer hito es trazado por una Constitución Latinoamericana, la Constitución Mexicana de 1917, la primera Constitución social del mundo, la que introduce conceptos tales como la propiedad originaria de la Nación sobre las tierras y las aguas, el derecho de propiedad con función social, la protección de los recursos naturales y el régimen de economía mixta.

Pero contra lo que se podía creer, en sus orígenes, el uso del concepto de Constitución Económica no tuvo conexión directa con el mundo del derecho ${ }^{5}$; a los principios y reglas fundamentales por los que se rige. Se encuentra en Alemania, en 1932, uno de los primeros antecedentes en su utilización por Beckerath, quien definía a la Constitución Económica como la ordenación de la propiedad, del contrato y del trabajo, de la forma y extensión de la intervención del Estado, así como la organización y técnica de la producción y la distribución.

Es preciso reconocer que su origen histórico del concepto de Constitución Económica y del llamado Derecho Constitucional Económico tuvo directamente conectado por el fenómeno de la socialización, cuyo instrumento principal es a intervención del Estado en la economía ${ }^{6}$.

En el caso del Perú, el sistema económico constitucionalizado es el de una economía de mercado del Estado Social, es decir, el de una economía social de mercado, con valores no solo económicos, que suele dejar un amplio margen de acción al poder político para configurar un modelo económico, resultado de la combinación de elementos heterogéneos, procedentes de las distintas formas de concebir la economía del mercado e inspirados tanto en postulados del neocapitalismo contemporáneo como del socialismo democrático. ${ }^{7}$

\section{EL ANALISIS ECONOMICO DEL DERECHO CONSTITUCIONAL}

La aplicación de la teoría económica -más precisamente, de la microeconomía- al derecho ha generado desde siempre un cierto rechazo de parte de la comunidad jurídica, toda vez que la visión economicista de la norma, a juicio de los doctos en leyes, reduce a conceptos de eficiencia, relación costo-beneficio, utilidad e

\footnotetext{
${ }^{5}$ RETORTILLO BAQUER, Martin 1988, p. 286.

${ }^{6}$ LOJENDIO, óp. Cit. P. 85.

${ }^{7}$ KRESALJA 2004, P. 519.
} 
incentivos cuestiones que trascienden en la sociedad y que no necesariamente responden a una filosofía de racionalidad en la elección entre cestas de mercado sino que se derivan de concepciones morales, sociales y culturales arraigadas en la población y a las cuales no se les puede eliminar con base en una justificación económica. Tal concepción ha sido aún más fuerte en el ámbito del derecho constitucional, pues si bien esta rama de derecho estudia la creación, modificación y aplicación de las normas que rigen toda la vida política, jurídica y económica del Estado, el análisis obedece a una concepción histórica determinada, en la que los valores imperantes en la sociedad al momento de su estudio se constituyen en el punto de partida, el cual se cree que es inmodificable, pues constituye la soberanía del pueblo, que es en quien está depositado el poder constituyente.

No obstante, de cara a la realidad, es claro que todas las personas, al momento de tomar cualquier decisión, analizamos los pros y los contras de aquélla, no sólo frente a la alternativa en sí, sino respecto de sus repercusiones futuras; adoptamos las opciones que más nos convengan, aunque sea sólo de manera inmediata y aun con el riesgo de perjudicar a otros, todo con el fin de satisfacer nuestras propias necesidades. Esto, en términos microeconómicos, se conoce como la "relación costo-beneficio", cuyo fin último consiste en la "maximización de la función de utilidad" de cada "agente económico" que se mueve en un "mercado", con miras a obtener la mejor opción posible partiendo de los escasos recursos que se tienen, de manera que se opte por la alternativa más "eficiente".

Es así como, aunque parezcan muy distantes para los juristas, el derecho y la economía, por el contrario, van muy de la mano. Todas las concepciones históricas de la sociedad y del Estado han aparejado el análisis y replanteamiento de los modelos económicos, especialmente si se tiene en cuenta que el patrimonio público juega un papel trascendental para cualquier conglomerado por la necesidad de satisfacción de ciertas necesidades comunes que justifican la unión de las personas y la existencia de regímenes de convivencia entre ellas.

A partir de la conciencia adquirida -especialmente por los economistas- sobre la importancia de mejorar las políticas estatales y crear cambios sustanciales en la concepción real del Estado, se inicia el estudio del derecho constitucional desde la perspectiva microeconómica y de su influencia en el funcionamiento de la economía en los diferentes estados. A esto se le conoce, entonces, como el "análisis económico del derecho constitucional", caracterizado principalmente por el estudio de las políticas públicas y de las instituciones en el marco de un modelo de Estado determinado, tanto desde la perspectiva positiva (de la explicación y predicción de relaciones de causa y efecto de lo existente) como en la normativa (del deber ser, más allá de la explicación y la predicción, utilizando juicios de valor).

Así también, podemos señalar que el análisis económico del Derecho se presenta como una metodología moderna que ofrece criterios interdisciplinarios para comprender el derecho desde una perspectiva nueva, relacionada estrechamente a la ciencia jurídica con fenómenos sociales económicos propios de la actividad empresarial de personas naturales o jurídicas. 
José Román Cossío ${ }^{8}$, en su libro Derecho y Análisis Económico explica que la transformación de las conductas a conductas económicas se presenta por que en un contexto de escases de recursos el sujeto agente económico actúa buscando maximizar su utilidad, manteniendo estables sus preferencias, Entonces podemos afirmar que el análisis económico del Derecho Constitucional no es un análisis de tipo normativo o exegético, sino más bien un método que analiza aquellas conductas humanas que se encuentran interrelacionadas de algún modo con el derecho.

\section{A MODO DE CONCLUSION}

- $\quad$ En el Perú existe un marco jurídico de rango constitucional que establece el sistema económico vigente y regula la actividad económica del Estado y de los particulares, que condicionan su validez a la observancia de sus principios, derechos y libertades.

- La Economía Social de Mercado como uno de los pilares del marco normativo económico según nuestra Carta Política de 1993, exige que el Estado cumpla una serie de funciones de modo que garantice los derechos fundamentales que ésta reconoce. En este sentido, la Economía Social de Mercado como modelo propio del Estado Social de Derecho busca integrar y conjugar de manera razonable y proporcional la libertad individual y subsidiariedad estatal, y la igualdad y la solidaridad social.

- El Tribunal Constitucional es el órgano encargado por la Constitución de determinar si los actos públicos o privados, incluso en el ámbito económico, son válidos por estar conforme a la Constitución, caso contrario serán declarados nulos.

\section{BIBLIOGRAFIA CONSULTADA}

- $\quad$ Constitución Política del Perú, Titulo II, Cap.III, Art. 6 a 31.

- Héctor Cuadra, "Reflexiones sobre derecho económico", en «Estudios de derecho económico» I, México: UNAM, 1976; Jorge Witker, «Derecho económico», México: Harla, 1985; Andrés Serra Rojas, «Derecho económico», México: Porrúa, 1990.

- $\quad$ PINKAS, Flint, Tratado de Defensa de la Libre Competencia "Legislación, Doctrina y Jurisprudencia Regulatoria de la Libre Competencia", Ed. Fondo Editorial PUCP. Lima.

${ }^{8}$ COSSIO DIAZ, José Román, Derecho y Análisis Económico, México D.F. Instituto Tecnológico Autónomo de México y Fondo de Cultura Económica, 1997, p. 229. 
- CASANOVA CLAROS, Mariella (2008). Responsabilidad social comparativa. En Revista Vox luris $\mathrm{N}^{\circ}$ XVII.

- COOTER y ULLEN (1998), Derecho \& Economía, Teoría Económica del Contrato.

- $\quad$ KRESALJA ROSELLO, Baldo (2004) El Constitucionalismo Económico y las Características del Sistema Económico del Perú. En el libro Homenaje a Jorge Avendaño Valdez. Ed. Fondo Editorial PUCP. Lima.

- CAStillo VASQueZ, Fernando (1992) Aspectos doctrinales en: Elementos económicos en la Constitución Política. Cap. II, p. 31 a 46.

- KRESALJA, BALDO Y OCHOA, Cesar (2009) Derecho Constitucional Económico, Capítulo VIII: Del Estado Social de Derecho el Estado de Justicia y Cultura, Fondo Editorial PUCP. Lima. 